Article

\title{
Hybrid Modelling and Sliding Mode Control of Semi-Active Suspension Systems for Both Ride Comfort and Road-Holding
}

\author{
Ayman Aljarbouh *(D) and Muhammad Fayaz (D) \\ Department of Computer Science, University of Central Asia, 310 Lenin Street, Naryn 722918, Kyrgyzstan; \\ muhammad.fayaz@ucentralasia.org \\ * Correspondence: ayman.aljarbouh@ucentralasia.org; Tel.: +996-770-822-972
}

Received: 6 July 2020; Accepted: 27 July 2020; Published: 3 August 2020

\begin{abstract}
Rigorous model-based design and control for intelligent vehicle suspension systems play an important role in providing better driving characteristics such as passenger comfort and road-holding capability. This paper investigates a new technique for modelling, simulation and control of semi-active suspension systems supporting both ride comfort and road-holding driving characteristics and implements the technique in accordance with the functional mock-up interface standard FMI 2.0. Firstly, we provide a control-oriented hybrid model of a quarter car semi-active suspension system. The resulting quarter car hybrid model is used to develop a sliding mode controller that supports both ride comfort and road-holding capability. Both the hybrid model and controller are then implemented conforming to the functional mock-up interface standard FMI 2.0. The aim of the FMI-based implementation is to serve as a portable test bench for control applications of vehicle suspension systems. It fully supports the exchange of the suspension system components as functional mock-up units (FMUs) among different modelling and simulation platforms, which allows re-usability and facilitates the interoperation and integration of the suspension system components with embedded software components. The concepts are validated with simulation results throughout the paper.
\end{abstract}

Keywords: semi-active suspension; modelling; sliding mode control; functional mock-up interface; hybrid automata

\section{Introduction}

With the increasing level of technology integration in road vehicles, the automotive industry is focusing more on delivering better driving characteristics, such as passenger comfort, road-holding capability and energy consumption. A rigorous model-based design and control for intelligent vehicle suspension systems play an important role in providing such characteristics at a small cost. A vehicle suspension can be seen as a rigid body having a symmetrical structure. In general, there are three different types of vehicle suspension systems, classified as passive suspension, semi-active suspension and active suspension [1-5]. Passive suspension absorbs the road perturbations by using conventional springs and passive dampers installed between the sprung mass (representing the vehicle body) and the unsprung mass (representing the wheel-axle assembly). Passive suspension has good performance only in a limited range of operating conditions. Active suspension improves the passive components by using an external power source to supply additional control force determined by a feedback control law based on the input data from sensors that measure the displacement and acceleration of various suspension parts. Semi-active suspension is in between the two aforementioned suspensions and uses a conventional spring and controlled semi-active damper, where a control input is used to adjust the damping force based on measurements from sensors installed in the vehicle 
body [6]. Semi-active suspension can provide most of the performance characteristics provided by active suspension and is more economic in operation than active suspension in terms of cost and energy consumption [7-9]. In this study, we focus on semi-active suspension systems that use electro-rheological (ER) dampers. ER dampers are hydraulic devices filled with electro-rheological fluid that changes its apparent viscosity when applying an external electric field. In terms of ER damper modelling studies, these either use non-parametric approaches (i.e., damping force modelled by special well-suited functions or artificial intelligence methods) or parametric approaches (i.e., a damping force model is described by mechanical laws and validated by identification experiments for different kinematic excitations). The goal of providing better driving characteristics, including ride comfort and road-holding, can be achieved by a successful implementation of an intelligent suspension system by using an accurate dynamic model of vehicle suspension and a suitable control strategy, where both the model and controller are able to run in real-time in embedded electronic control units (ECUs).

Various control strategies and models have been proposed for semi-active vehicle suspension systems. This includes the use of non-parametric models [10-12] and parametric models [13-16], as well as different control strategies such as LQ (Linear-Quadratic)/LQG (Linear-Quadratic-Gaussian) control [17], $H_{\infty}$ control [18], optimal control [19,20], fuzzy Logic control [21,22], PID control [23] and control strategies based on neural networks [24,25] and genetic algorithms [26]. However, the implementation of vehicle suspension models and controllers for embedded software requires very high efforts in creation, simplification, discretization and numerical solution, implementation, testing and fulfilling coding requirements, because no appropriate tool support is available and all parts have to be manually developed. This limits the usage in production code software on automotive ECUs significantly and is the major reason why currently, only a few physics-based models and controllers are utilized in automotive ECUs. In addition, there is today no generic simulation solution supporting model and control export suitable for direct integration into automotive embedded systems. Such integration is done today through specific manual integration, leading to resource, time and cost intensive activities, losing models' continuity and facing complexity limitations. These limitations are today a bottleneck for integrating smarter controllers for more efficient vehicle suspension systems.

The functional mock-up interface for embedded systems (eFMI) is a promising solution that aims to deal with this problem by providing a generic way, shared among the industry, of integrating models and control software into embedded systems. It acts as an interface between ECU software and the very different modelling and simulation tools and uses the core functionality of the functional mock-up interface standard FMI 2.0 [27].

In this paper, we investigate a new technique for modelling, simulation and control of semi-active suspension systems supporting both ride comfort and road-holding driving characteristics, and we implement the technique in accordance with the functional mock-up interface standard FMI 2.0. Firstly, we derive a control-oriented hybrid model of a quarter car semi-active suspension system that takes into account the non-linear behaviour of electro-rheological dampers used in semi-active suspension systems. The resulting quarter car hybrid model is used to develop a sliding mode controller that supports both ride comfort and road-holding capability. Both the hybrid model and controller are then implemented conforming to the functional mock-up interface standard FMI 2.0 for model exchange. The aim of the FMI-based implementation is to serve as a portable test bench for control applications of vehicle suspension systems.

The paper is organized as follows: Section 2 introduces the hybrid automata modelling formalism. Section 3 presents a dynamic model of a semi-active ER damper and its hybrid automaton. Section 4 describes the quarter car suspension model. Section 5 presents the sliding mode controller design with the support of both ride comfort and road-holding capability. Section 6 discusses the prototype implementation and simulation results. Finally, conclusion and perspectives are given in Section 7. 


\section{Hybrid Automata}

Hybrid automata is a modelling technique that is used to model the continuous and discrete behaviours in hybrid dynamical systems [28-30].

Definition 1. (Hybrid automaton)

A hybrid automaton $\mathcal{H}$ is a tuple $\mathcal{H}=(Q, X$, Init, $F, I, E, G, R)$ [31,32] where:

- $Q$ is a set of discrete states $q_{i} \in Q$;

- $X$ is a set of continuous state vectors $x \in X \subseteq \mathbb{R}^{n}$;

- Init is a set of initial hybrid states $\left(q_{0}, x(0)\right) \in$ Init $\subset Q \times \mathbb{R}^{n}$;

- $\quad F$ is a set of vector fields $f\left(q_{i}, x\right) \in F: Q \times \mathbb{R}^{n} \rightarrow \mathbb{R}^{n}$;

- I is a set of continuous invariants $\operatorname{Inv}\left(q_{i}\right) \in I: Q \rightarrow \mathbb{R}^{n}$, where $\operatorname{Inv}\left(q_{i}\right)$ restricts the continuous evolution within $q_{i} \in Q$;

- $E$ is a set of discrete transitions $e_{i} \in E \subseteq Q \times Q$ to switch between discrete states $q_{i} \in Q$;

- $G$ is a set of guard conditions $\mathcal{G}\left(e_{i}\right) \in G: E \rightarrow \mathbb{R}^{n}$;

- $\quad R$ is a set of reset maps $\mathcal{R}\left(e_{i}, x\right) \in R: E \rightarrow \mathbb{R}^{n} \times \mathbb{R}^{n}$.

A hybrid state is defined as a pair $\left(q_{i}, x\right)$ of a discrete state $q_{i} \in Q$ and a continuous state $x \in \mathbb{R}^{n}$.

\section{Modelling of Electro-Rheological Damper}

Figure 1 shows the schematic representation of an electro-rheological (ER) semi-active damper. The damper consists of an outer cylinder that is connected to the ground, an inner cylinder that is connected to a voltage source, an upper chamber whose pressure is denoted by $P_{1}$, a lower chamber whose pressure is denoted by $P_{2}$ and a gas chamber whose pressure is denoted by $P_{a}$. The relation between pressures $P_{1}, P_{2}$ and $P_{a}$ is given by:

$$
P_{2}=P_{a}+\Delta P_{a} \simeq P_{a}, \quad P_{1}=P_{a}-\Delta P
$$

where $\Delta P_{a}$ is the pressure difference between the gas chamber and the lower chamber, which can be neglected, and $\Delta P$ is the difference between pressures $P_{1}$ and $P_{2}$ [33], given by:

$$
\Delta P=\frac{6 \mu L_{d}}{\pi d^{3} R_{d}}\left(A_{p}-A_{s}\right) \dot{z}_{d e f}+c \frac{L_{d}}{d} \delta
$$

where $d$ is the gap between the outer and inner cylinders, $L_{d}$ and $R_{d}$ are the length and radius of the inner cylinder, respectively, $A_{p}$ is the piston cross-sectional area, $A_{s}$ is the piston shaft cross-sectional area, $z_{\text {def }}$ is the excitation displacement (i.e., suspension system deflection), $\mu$ is the electro-rheological post-yield viscosity, $\delta$ is the electro-rheological fluid stress at the yield strength due to the applied electric field and $c$ is a coefficient whose value depends on the velocity of the electro-rheological fluid flow and approximated by:

$$
c=2.07+\frac{12 \mu\left(A_{p}-A_{s}\right) \dot{z}_{d e f}}{12 \mu\left(A_{p}-A_{s}\right) \dot{z}_{d e f}+0.8 \pi R_{d} d^{2} \delta}
$$

The semi-active damping force $F_{D}$ generated by the damper can be expressed as [33]:

$$
F_{D}=P_{a} A_{s}+\Delta P\left(A_{p}-A_{s}\right)
$$

which yields from (2):

$$
F_{D}=P_{a} A_{s}+\frac{6 \mu L_{d}}{\pi d^{3} R_{d}}\left(A_{p}-A_{s}\right)^{2} \dot{z}_{d e f}+\frac{c L_{d}\left(A_{p}-A_{s}\right)}{d} \delta
$$


The electro-rheological yield stress $\delta$ can be approximated by:

$$
\delta=\alpha E^{\beta} \operatorname{sign}\left(\dot{z}_{\text {def }}\right)=\alpha\left(-\frac{U_{m}}{d} v\right)^{\beta} \operatorname{sign}\left(\dot{z}_{\text {def }}\right)
$$

where $U_{m}$ is the maximum voltage, $E$ is the electric field, $v$ is the control electrical signal with pulse-width modulation and $\alpha, \beta$ are electro-rheological fluid parameters.

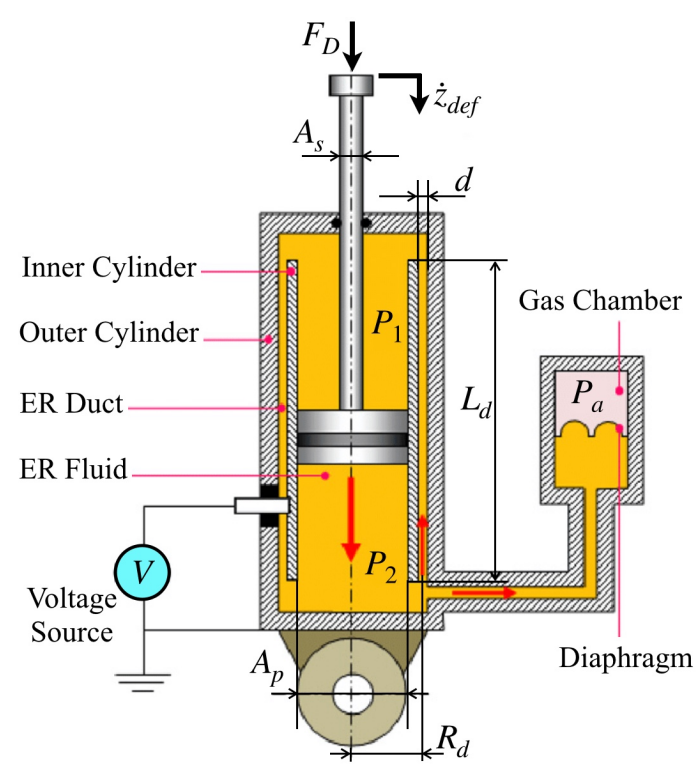

Figure 1. Schematic of the electro-rheological (ER) damper.

The damping force $F_{D}$ in (5) can be approximated, taking into account its dynamic characteristics and the approximation of $\delta$, as:

$$
\begin{aligned}
& F_{D}=k_{e} z_{d e f}+c_{e} \dot{z}_{d e f}+F_{E R} \\
& \dot{F}_{E R}=-\frac{1}{\tau} F_{E R}+\frac{1}{\tau} \psi \operatorname{sign}\left(\dot{z}_{d e f}\right) \\
& \psi=\sigma v^{\beta}
\end{aligned}
$$

with:

$$
\begin{aligned}
& c_{e}=\frac{6 \mu L_{d}}{\pi d^{3} R_{d}}\left(A_{p}-A_{s}\right)^{2} \\
& \sigma=\frac{c L_{d}\left(A_{p}-A_{s}\right)}{d} \alpha\left(-\frac{U_{m}}{d}\right)^{\beta}
\end{aligned}
$$

where $k_{e}$ is a tunable parameter representing the electro-rheological effective stiffness, $c_{e}$ is a tunable parameter representing the electro-rheological effective damping, $F_{E R}$ is the controllable damping force, which is tunable by the applied electric field, $\psi$ is the control input and $\tau$ is the time constant of the ER damper.

Denote $x=\left[x_{1}, x_{2}, x_{3}\right]^{T}=\left[z_{\text {def }}, \dot{z}_{\text {def }}, F_{E R}\right]^{T}$ as a continuous state vector and $\bar{A}$ as the closure of an open subset $A$. Figure 2 shows the hybrid automaton representation of the field-dependent damping force dynamics $\dot{F}_{E R}$. The hybrid automaton consists of two discrete states $q_{1}$ and $q_{2}$ having two disjoint invariants $\operatorname{Inv}\left(q_{1}\right)=\left\{x \in \mathbb{R}^{3}: x_{2}<0\right\}$ and $\operatorname{Inv}\left(q_{2}\right)=\left\{x \in \mathbb{R}^{3}: x_{2}>0\right\}$, respectively. A discrete transition from $q_{1}$ and $q_{2}$ is triggered when enabling the guard condition $\mathcal{G}\left(q_{1}, q_{2}\right)=\left\{x \in \mathbb{R}^{3}: x_{2} \geq 0\right\}$, and a discrete transition from $q_{2}$ and $q_{1}$ is triggered when enabling the guard condition $\mathcal{G}\left(q_{2}, q_{1}\right)=\left\{x \in \mathbb{R}^{3}: x_{2} \leq 0\right\}$. The dynamics of the field-dependent 
damping force is discontinuous on a hyper switching manifold $\Gamma_{1}$ defined as the zeros of a scalar function that represents the excitation velocity $\dot{z}_{\text {def }}$ of the ER damper, namely $\Gamma_{1}=\mathcal{G}\left(q_{1}, q_{2}\right) \cap \overline{\operatorname{Inv}\left(q_{1}\right)}=\mathcal{G}\left(q_{2}, q_{1}\right) \cap \overline{\operatorname{Inv}\left(q_{2}\right)}=\left\{x \in \mathbb{R}^{3}: x_{2}=0\right\}$.

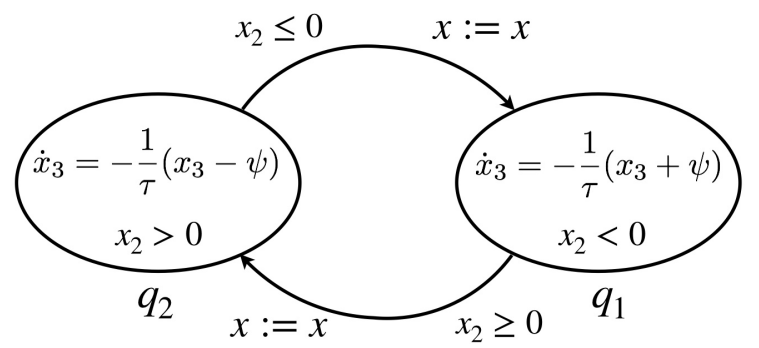

Figure 2. The hybrid automaton of the field-dependent damping force dynamics.

\section{The Quarter Car Suspension Model}

With the assumption of a symmetrical structure for the full car suspension systems, one can simplify a full car suspension model to a quarter car suspension model. Figure 3 shows a quarter car suspension model having two degrees of freedom (2 DOF). The model comprises two parts, the sprung mass $m_{s}$ that represents the car quarter-body and the unsprung mass $m_{u}$ that represents the one wheel-axle assembly. Both the sprung mass and unsprung mass have freedom of motion in the vertical direction; thus, the two degrees of freedom are represented by the bounces of the two masses. The suspension system consists of a semi-active ER damper and a linear suspension spring. The tire is represented by a simple linear spring. By the application of Newton's second law, the equations of motion for the quarter car model are given by:

$$
\begin{aligned}
& m_{s} \ddot{z}_{s}=-\left(k_{s}+k_{e}\right)\left(z_{s}-z_{u}\right)-c_{e}\left(\dot{z}_{s}-\dot{z}_{u}\right)-F_{E R} \\
& m_{u} \ddot{z}_{u}=\left(k_{s}+k_{e}\right)\left(z_{s}-z_{u}\right)+c_{e}\left(\dot{z}_{s}-\dot{z}_{u}\right)+F_{E R}-k_{t}\left(z_{u}-z_{w}\right) \\
& \dot{F}_{E R}+\frac{1}{\tau} F_{E R}=g\left(v, \dot{z}_{s}-\dot{z}_{u}\right)=\frac{1}{\tau} \psi \operatorname{sign}\left(\dot{z}_{s}-\dot{z}_{u}\right), \quad \psi=\sigma v^{\beta}
\end{aligned}
$$

where $z_{s}, z_{u}$ and $z_{w}$ denote the car body vertical displacement, the wheel-axle vertical displacement and the road disturbance, respectively, $k_{s}$ is the stiffness of the suspension spring, $k_{t}$ is the tire stiffness, $k_{e}$ is the passive stiffness of the damper, $c_{e}$ is the passive damping of the damper, $F_{E R}$ is the field-dependent controllable damping force, $\tau$ is the damper time constant and $\psi$ is the control input.

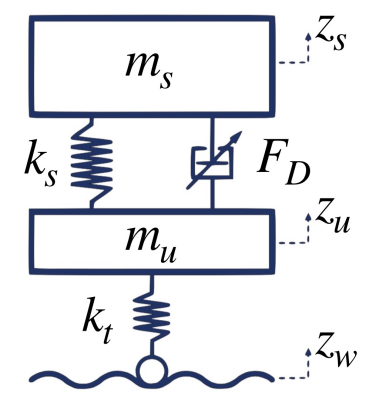

Figure 3. Schematic of the 2 DOF quarter car suspension system.

By defining the state variable vector as $x=\left[\begin{array}{lllll}z_{s} & \dot{z}_{s} & z_{u} & \dot{z}_{u} & F_{E R}\end{array}\right]^{T}=\left[\begin{array}{lllll}x_{1} & x_{2} & x_{3} & x_{4} & x_{5}\end{array}\right]^{T}$, the control input as $u=\psi$, the disturbance vector as $w=z_{w}$ and letting $\xi=\operatorname{sgn}\left(\dot{z}_{s}-\dot{z}_{u}\right)$, we obtain the following state space equation:

$$
\dot{x}=A x+B u+L w
$$


where:

$$
\boldsymbol{A}=\left[\begin{array}{ccccc}
0 & 1 & 0 & 0 & 0 \\
-\frac{\left(k_{s}+k_{e}\right)}{m_{s}} & -\frac{c_{e}}{m_{s}} & \frac{\left(k_{s}+k_{e}\right)}{m_{s}} & \frac{\mathcal{c}_{e}}{m_{s}} & -\frac{1}{m_{s}} \\
0 & 0 & 0 & 1 & 0 \\
\frac{\left(k_{s}+k_{e}\right)}{m_{u}} & \frac{\mathcal{c}_{e}}{m_{u}} & -\frac{\left(k_{s}+k_{e}+k_{t}\right)}{m_{u}} & -\frac{c_{e}}{m_{u}} & \frac{1}{m_{u}} \\
0 & 0 & 0 & 0 & -\frac{1}{\tau}
\end{array}\right], \quad \boldsymbol{B}=\left[\begin{array}{l}
0 \\
0 \\
0 \\
0 \\
\frac{\xi}{\tau}
\end{array}\right], \quad L=\left[\begin{array}{c}
0 \\
0 \\
0 \\
\frac{k_{t}}{m_{u}} \\
0
\end{array}\right]
$$

The continuous state space of the quarter car suspension model is split into two disjoint invariants by a hyper switching manifold $\Gamma_{2}$ given by:

$$
\Gamma_{2}=\left\{x \in \mathbb{R}^{5}: x_{2}-x_{4}=0\right\}
$$

Figure 4 shows the hybrid automaton of the quarter car suspension model. The vector fields and invariants for each discrete state are given in Table 1, and the guard conditions and reset maps for each discrete transition $e_{i}$ are given in Table 2 .

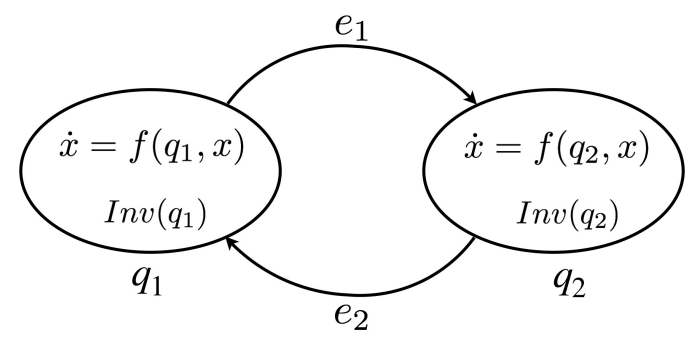

Figure 4. The hybrid automaton of the quarter car suspension model.

Table 1. The vector fields and invariants of the discrete states in Figure 4.

\begin{tabular}{crr}
\hline Discrete State $q_{i}$ & \multicolumn{1}{c}{ Dynamics $f\left(q_{i}, x\right)$} & Invariant Inv $\left(\boldsymbol{q}_{\boldsymbol{i}}\right)$ \\
\hline$\dot{x}_{1}$ & $=x_{2}$ & \\
$\dot{x}_{2}$ & $=-\frac{\left(k_{s}+k_{e}\right)}{m_{s}}\left(x_{1}-x_{3}\right)-\frac{c_{e}}{m_{s}}\left(x_{2}-x_{4}\right)-\frac{1}{m_{s}} x_{5}$ & \\
$\dot{q}_{3}$ & $=x_{4}$ & \\
& & \\
$\dot{x}_{4}$ & $=\frac{\left(k_{s}+k_{e}\right)}{m_{u}}\left(x_{1}-x_{3}\right)+\frac{c_{e}}{m_{u}}\left(x_{2}-x_{4}\right)+\frac{1}{m_{u}} x_{5}-\frac{k_{t}}{m_{u}}\left(x_{3}-w\right)$ & \\
$\dot{x}_{5}$ & $=-\frac{1}{\tau}\left(x_{5}+u\right)$ & \\
$\dot{x}_{1}$ & $=x_{2}$ & \\
$\dot{x}_{2}$ & $=-\frac{\left(k_{s}+k_{e}\right)}{m_{s}}\left(x_{1}-x_{3}\right)-\frac{c_{e}}{m_{s}}\left(x_{2}-x_{4}\right)-\frac{1}{m_{s}} x_{5}$ & $x_{2}-x_{4}>0$ \\
$\dot{x}_{3}$ & $=x_{4}$ & \\
$\dot{x}_{4}$ & $=\frac{\left(k_{s}+k_{e}\right)}{m_{u}}\left(x_{1}-x_{3}\right)+\frac{c_{e}}{m_{u}}\left(x_{2}-x_{4}\right)+\frac{1}{m_{u}} x_{5}-\frac{k_{t}}{m_{u}}\left(x_{3}-w\right)$ & \\
$\dot{x}_{5}$ & $=-\frac{1}{\tau}\left(x_{5}-u\right)$ & \\
\hline
\end{tabular}

Table 2. The guard conditions and reset maps of the discrete transitions in Figure 4.

\begin{tabular}{ccc}
\hline Transition $\boldsymbol{e}_{\boldsymbol{i}}$ & Reset $\mathcal{R}\left(\boldsymbol{e}_{\boldsymbol{i}}, \boldsymbol{x}\right)$ & Guard $\mathcal{G}\left(\boldsymbol{e}_{\boldsymbol{i}}\right)$ \\
\hline$e_{1}$ & $x:=x$ & $x_{2}-x_{4} \geq 0$ \\
\hline$e_{2}$ & $x:=x$ & $x_{2}-x_{4} \leq 0$ \\
\hline
\end{tabular}

\section{The Sliding Mode Controller Design}

The main objective of the sliding mode controller is to provide both ride comfort and road-holding driving characteristics by adaptively adjusting the damping force. The control law is determined in such a way that the error dynamics between the actual quarter car model and the desired reference model states are minimized using a sliding mode. The advantage of the sliding mode controller is that it can achieve high robustness against the damper's non-linear properties. 
As the first step in designing the sliding mode controller, we use the hybrid quarter car suspension model from Section 4 to derive an ideal reference model that specifies the desired driving performance in terms of ride comfort and road-holding capability. The ideal reference model includes a combination of both the ideal skyhook damping concept (for ride comfort) and ideal groundhook damping concept (for road-holding capability); see Figure 5. In the ideal skyhook, the damping is proportional to the quarter-body sprung mass absolute velocity. In the ideal groundhook, the damping is proportional to the unsprung mass absolute velocity. The equations for the desired ride comfort and desired road-holding motions are given by:

$$
\begin{aligned}
& m_{s} \dot{x}_{2 d}=-\left(k_{s}+k_{e}\right)\left(x_{1 d}-x_{3}\right)-c_{e}\left(x_{2 d}-x_{4}\right)-c_{s} x_{2 d} \\
& m_{u} \dot{x}_{4 d}=\left(k_{s}+k_{e}\right)\left(x_{1}-x_{3 d}\right)+c_{e}\left(x_{2}-x_{4 d}\right)-c_{g} x_{4 d}-k_{t}\left(x_{3 d}-w\right)
\end{aligned}
$$

where $x_{1 d}$ and $x_{2 d}$ are the desired sprung mass displacement and velocity, respectively, $x_{3 d}$ and $x_{4 d}$ are the desired unsprung mass displacement and velocity, respectively, and $c_{s}$ and $c_{g}$ are the ideal ride comfort and road-holding damping coefficients, respectively, given by:

$$
\begin{gathered}
c_{s}=\left\{\begin{array}{lll}
c_{s_{\max }} & \text { if } & x_{2 d}\left(x_{2 d}-x_{4}\right) \geq 0 \\
0 & \text { if } & x_{2 d}\left(x_{2 d}-x_{4}\right)<0
\end{array}\right. \\
c_{g}=\left\{\begin{array}{lll}
c_{g_{\max }} & \text { if } & x_{4 d}\left(x_{2}-x_{4 d}\right) \leq 0 \\
0 & \text { if } & x_{4 d}\left(x_{2}-x_{4 d}\right)>0
\end{array}\right.
\end{gathered}
$$

where $c_{s_{\max }}$ and $c_{g_{\max }}$ are maximum damping coefficients. The aim of the sliding mode controller is to minimize the error signal between the quarter car suspension system and the reference model. We firstly define the tracking error vector as:

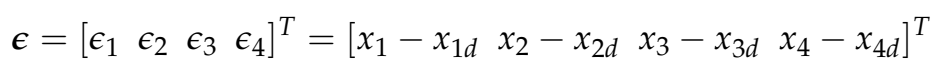

where $\epsilon_{1}$ and $\epsilon_{2}$ are the sprung mass displacement and velocity errors, respectively, and $\epsilon_{3}$ and $\epsilon_{4}$ are the unsprung mass displacement and velocity errors, respectively.

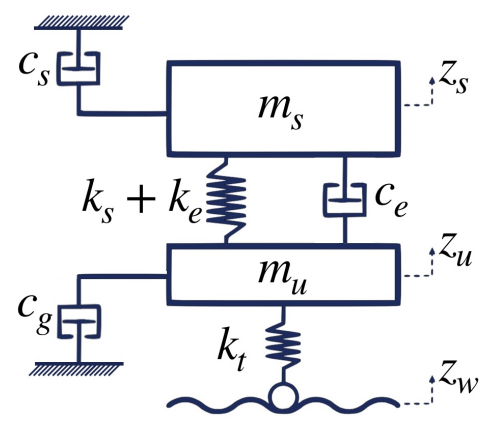

Figure 5. Schematic of the ideal skyhook and ideal groundhook.

To achieve the objective of providing both ride comfort and road-holding characteristics, we define the following sliding surfaces:

$$
\begin{aligned}
& s_{1}=\lambda_{1} \epsilon_{1}+\epsilon_{2}=\lambda_{1}\left(x_{1}-x_{1 d}\right)+\left(x_{2}-x_{2 d}\right) \\
& s_{2}=\lambda_{2} \epsilon_{3}+\epsilon_{4}=\lambda_{2}\left(x_{3}-x_{3 d}\right)+\left(x_{4}-x_{4 d}\right)
\end{aligned}
$$

where $s_{1}$ is the sliding surface for ride comfort, $s_{2}$ is the sliding surface for road-holding and $\lambda_{1}$ and $\lambda_{2}$ are positive constants that represent the slopes of sliding surfaces $s_{1}$ and $s_{2}$, respectively. 
The ride comfort tracking error dynamics is said to be in the sliding mode if $s_{1}=\dot{s}_{1}=0$, so the equivalent ride comfort damping force can be derived from (12), (18) and (23) as:

$$
F_{r c(e q)}=c_{s} x_{2}-\left(k_{s}+k_{e}\right) \epsilon_{1}-\left(c_{e}+c_{s}-\lambda_{1} m_{s}\right) \epsilon_{2}
$$

Similarly, the road-holding tracking error dynamics is said to be in the sliding mode if $s_{2}=\dot{s}_{2}=0$, so the equivalent road-holding damping force can be derived from (13), (19) and (24) as:

$$
F_{r h(e q)}=-c_{g} x_{4}+\left(k_{s}+k_{e}+k_{t}\right) \epsilon_{3}+\left(c_{e}+c_{g}-\lambda_{2} m_{u}\right) \epsilon_{4}
$$

To ensure that the sliding mode controller satisfies the sliding condition, discontinuous terms $\eta_{1} \operatorname{sgn}\left(s_{1}\right)$ and $\eta_{2} \operatorname{sgn}\left(s_{2}\right)$ are added to the equivalent damping forces $F_{r c(e q)}$ and $F_{r h(e q)}$, respectively, where $\eta_{1}$ and $\eta_{2}$ are positive constants chosen large enough so that the sliding condition is guaranteed under all quantified system perturbations. The ride comfort and road-holding damping forces $F_{r c(S M C)}$ and $F_{r h(S M C)}$ resulting from the sliding mode controller are then given by:

$$
\begin{aligned}
& F_{r c(S M C)}= \begin{cases}F_{r c(e q)}+\eta_{1} \operatorname{sgn}\left(s_{1}\right) & \text { if }\left(x_{2}-x_{4}\right)\left(F_{r c(e q)}+\eta_{1} \operatorname{sgn}\left(s_{1}\right)\right) \geq 0 \\
0 & \text { if }\left(x_{2}-x_{4}\right)\left(F_{r c(e q)}+\eta_{1} \operatorname{sgn}\left(s_{1}\right)\right)<0\end{cases} \\
& F_{r h(S M C)}= \begin{cases}F_{r h(e q)}+\eta_{2} \operatorname{sgn}\left(s_{2}\right) & \text { if }\left(x_{2}-x_{4}\right)\left(F_{r h(e q)}+\eta_{2} \operatorname{sgn}\left(s_{2}\right)\right) \leq 0 \\
0 & \text { if }\left(x_{2}-x_{4}\right)\left(F_{r h(e q)}+\eta_{2} \operatorname{sgn}\left(s_{2}\right)\right)>0\end{cases}
\end{aligned}
$$

Note that the conditions in (27) and (28) are imposed to ensure that the damping forces always act such that the suspended mass vibration is dissipated.

To combine both ride comfort and road-holding driving characteristics, the overall damping force generated from the sliding mode controller is represented by:

$$
F_{S M C}=\kappa F_{r c(S M C)}+(1-\kappa) F_{r h(S M C)}
$$

where $\kappa \in[0,1]$ is a relative ratio that is used to define the priority of the control design, whether it is fully ride comfort control (i.e., $\kappa=1$ ), or fully road-holding control (i.e., $\kappa=0$ ) or proportionally ride comfort and road-holding control (i.e., $\kappa \in(0,1))$.

Finally, the sliding mode control input $v_{S M C}$ is derived from (14) and given by:

$$
v_{S M C}=g^{-1}\left(F_{S M C}, x_{2}-x_{4}\right)=\sqrt[\beta]{\frac{1}{\sigma}\left(\tau \dot{F}_{S M C}+F_{S M C}\right) \operatorname{sign}\left(x_{2}-x_{4}\right)}
$$

\section{Prototype Implementation and Simulation Results}

To show the applicability of the proposed methods, a prototype implementation conforming to the functional mock-up interface standard FMI 2.0 is developed and validated through experimental simulation results. The functional mock-up interface standard FMI 2.0 is a free standard that defines a container and an interface to exchange dynamic models using a combination of XML files, binaries and C code [27]. The quarter car model, reference model and sliding mode controller are implemented as functional mock-up unit (FMU) components. Each FMU is a zip-file that consists of an XML-file containing information of all variables used in the FMU and a set of C-functions that represent all model/controller equations. The aim of the FMI-based implementation is to serve as a portable test bench for control applications of vehicle suspension systems. The implementation fully supports the exchange of the suspension system components as FMUs among different modelling and simulation platforms, which allows re-usability and facilitates the interoperation and integration of the suspension system components with embedded software components. 
To validate the prototype implementation, experimental work was performed on one quarter of the experimental test bench sketched in Figure 6. The experimental plant is approximately symmetric and equipped with four Fludicon ${ }^{\mathrm{TM}} \mathrm{ER}$ dampers controlled by a voltage source generated by amplifier modules CarCon2 ${ }^{\mathrm{TM}}$. The control input for each module is a PWM signal at $25 \mathrm{kHz}$. Each wheel is connected to a servomotor OMRON ${ }^{\mathrm{TM}}$ (with bandwidth $0-20 \mathrm{~Hz}$ ) to mimic the input road profile. The host PC uses a MATLAB/SimulinkTM control interface in which the FMU components of the quarter car model, reference model and sliding mode controller are imported for experimental validation. Initialization parameters and the road profile (input) are configured on the host PC as well. On the target PC, the FMU blocks are compiled and executed at a sampling time of $200 \mathrm{~Hz}$.

Table 3 shows the selected numerical values for the suspension model and control parameters. Figure 7 shows the random road perturbations' profile. The experimental validation results in the time domain are presented in Figure 8.

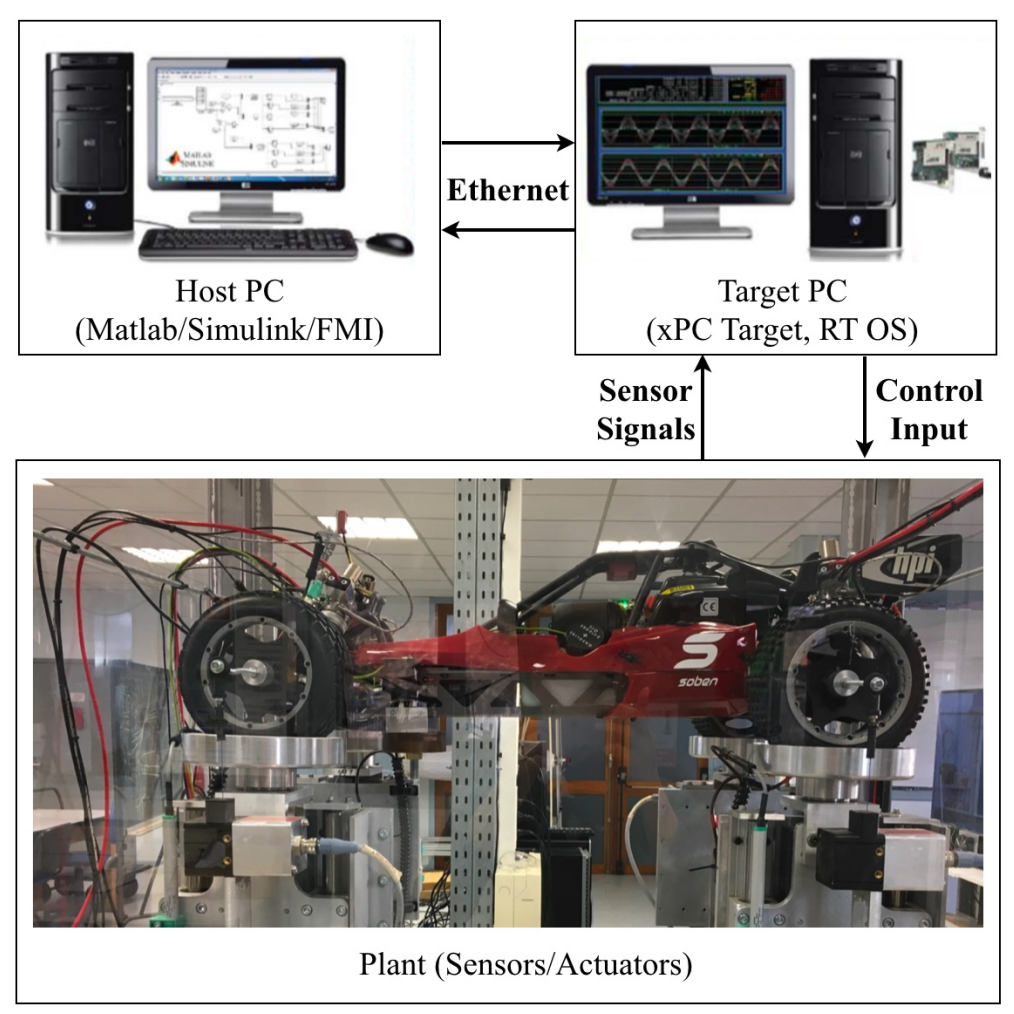

Figure 6. The test bench used for experimental validation.

Table 3. Numerical values for the suspension model and control parameters.

\begin{tabular}{lll}
\hline Parameter & Value & Unit \\
\hline$m_{s}$ & 2.28 & $\mathrm{~kg}$ \\
\hline$m_{u}$ & 0.26 & $\mathrm{~kg}$ \\
\hline$k_{s}$ & 1399 & $\mathrm{~N} / \mathrm{m}$ \\
\hline$k_{e}$ & 186 & $\mathrm{~N} / \mathrm{m}$ \\
\hline$c_{e}$ & 23 & $\mathrm{~N} \cdot \mathrm{s} / \mathrm{m}$ \\
\hline$k_{t}$ & 12,270 & $\mathrm{~N} / \mathrm{m}$ \\
\hline$\tau$ & 40 & $\mathrm{~ms}$ \\
\hline$c_{s_{\max }}$ & 5000 & $\mathrm{~N} \cdot \mathrm{s} / \mathrm{m}$ \\
\hline$c_{g_{\max }}$ & 3000 & $\mathrm{~N} \cdot \mathrm{s} / \mathrm{m}$ \\
\hline
\end{tabular}




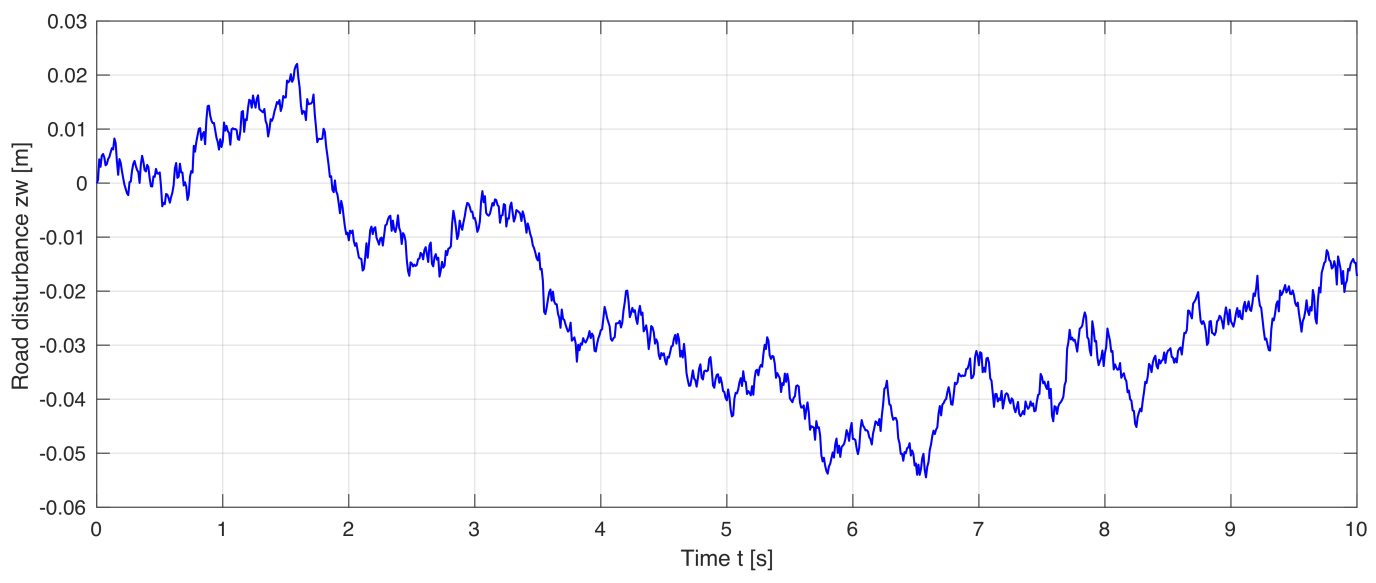

Figure 7. The random road perturbations' profile.

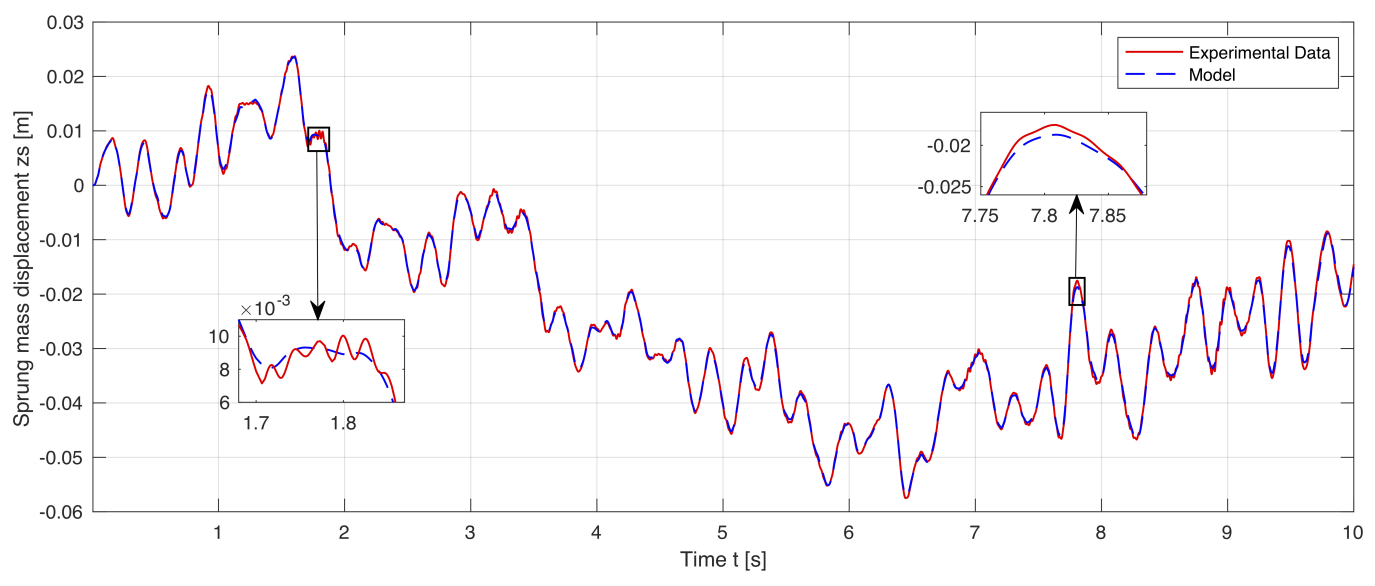

(a) Sprung mass displacement.

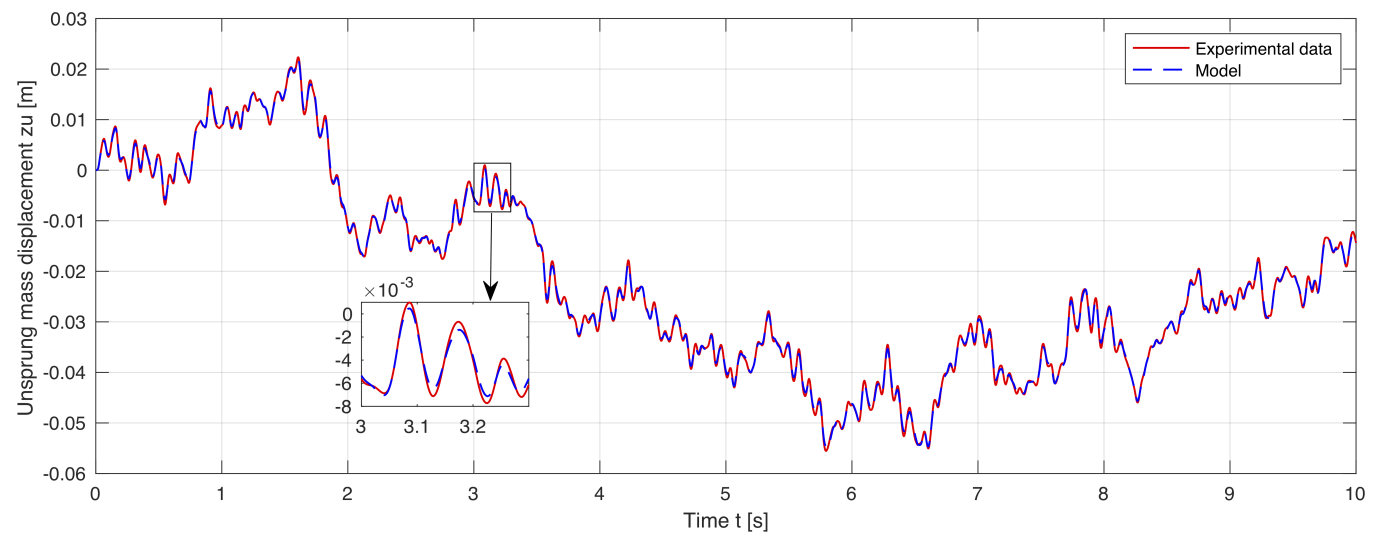

(b) Unsprung mass displacement.

Figure 8. Experimental validation: Experimental data versus model simulation.

The simulation results of passive and controlled displacements of both sprung and unsprung masses are presented in Figures 9 and 10 for comparison. Three different control cases were considered for three different driving characteristics, namely for full ride comfort (i.e., $\kappa=1$ ), full road-holding (i.e., $\kappa=0$ ) and proportionally both ride comfort and road-holding (i.e., $\kappa=0.6)$. It can be observed from Figures 9 and 10 that, in the case when the sliding mode control for ride comfort is effective (i.e., $\kappa=1$ ), the sprung mass vibrations decrease significantly, while the unsprung mass vibrations 
increase (i.e., road-holding deteriorates). In contrast, when the sliding mode control for road-holding is effective (i.e., $\kappa=0$ ), the unsprung mass vibrations decrease significantly, while the sprung mass vibrations increase (i.e., ride comfort deteriorates). When the sliding mode control applies for $60 \%$ ride comfort and $40 \%$ road-holding (i.e., $\kappa=0.6$ ), both sprung and unsprung mass vibrations proportionally decrease. This reflects the real physical trade-off between the road-holding and ride comfort driving characteristics.

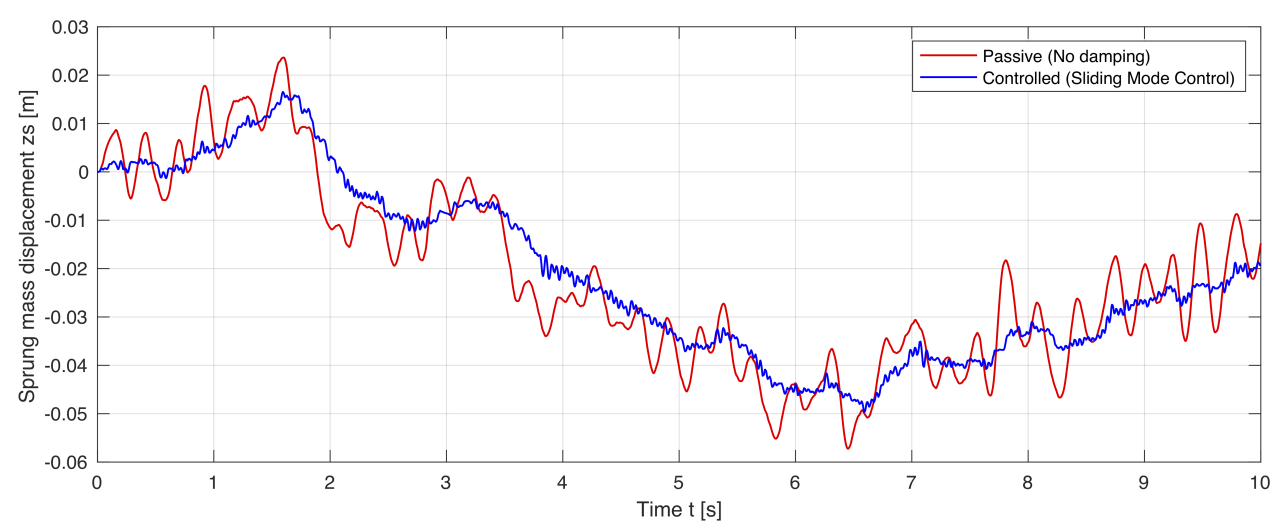

(a) Sprung mass displacement when $\alpha=1$.

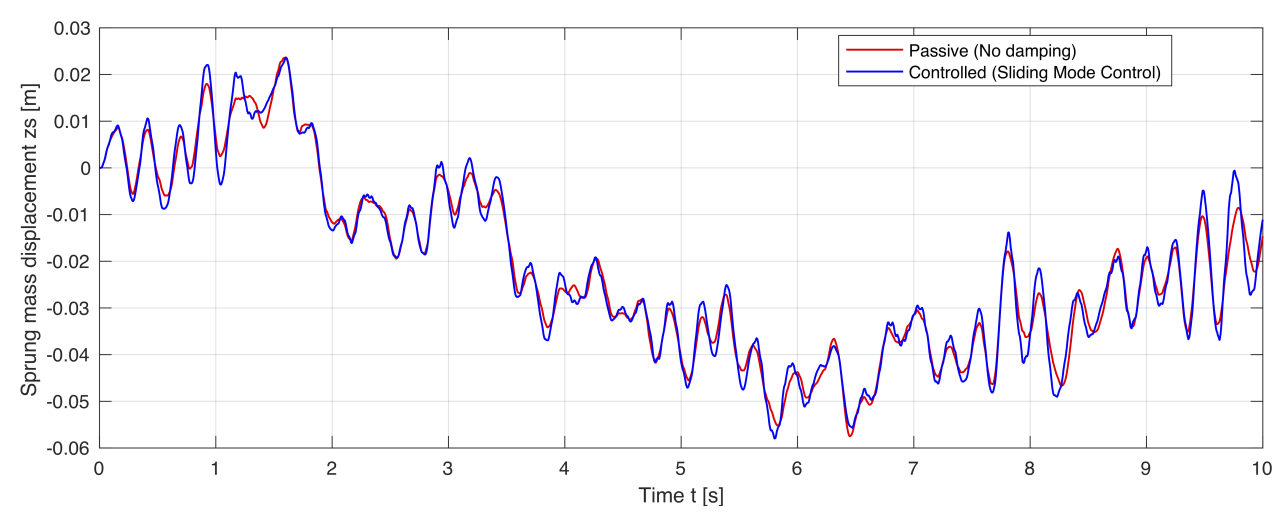

(b) Sprung mass displacement when $\alpha=0$.

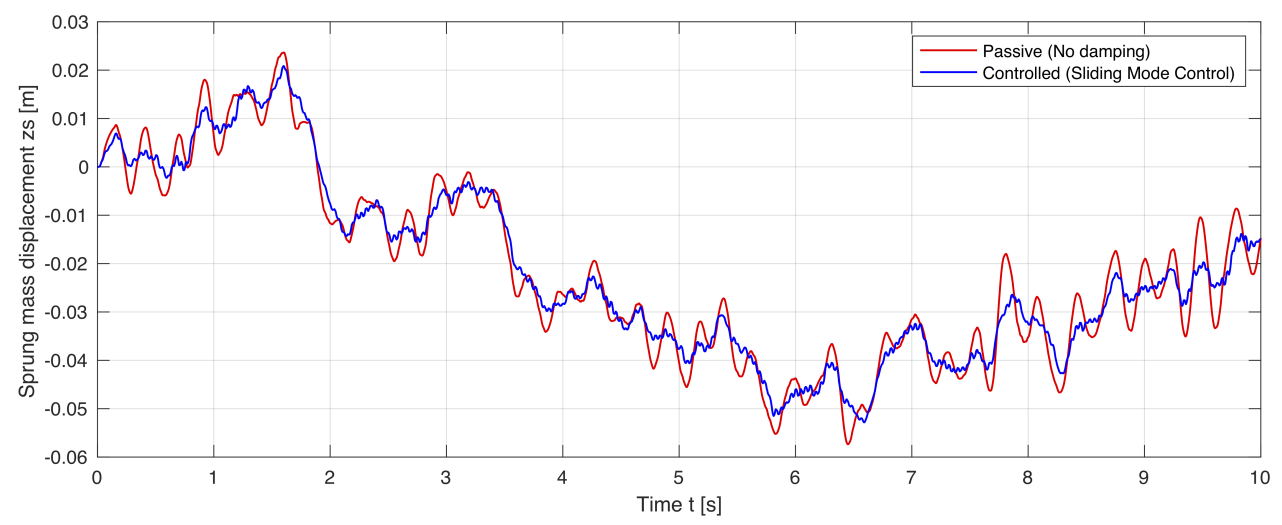

(c) Sprung mass displacement when $\alpha=0.6$.

Figure 9. The simulation of passive and controlled sprung mass displacements. 


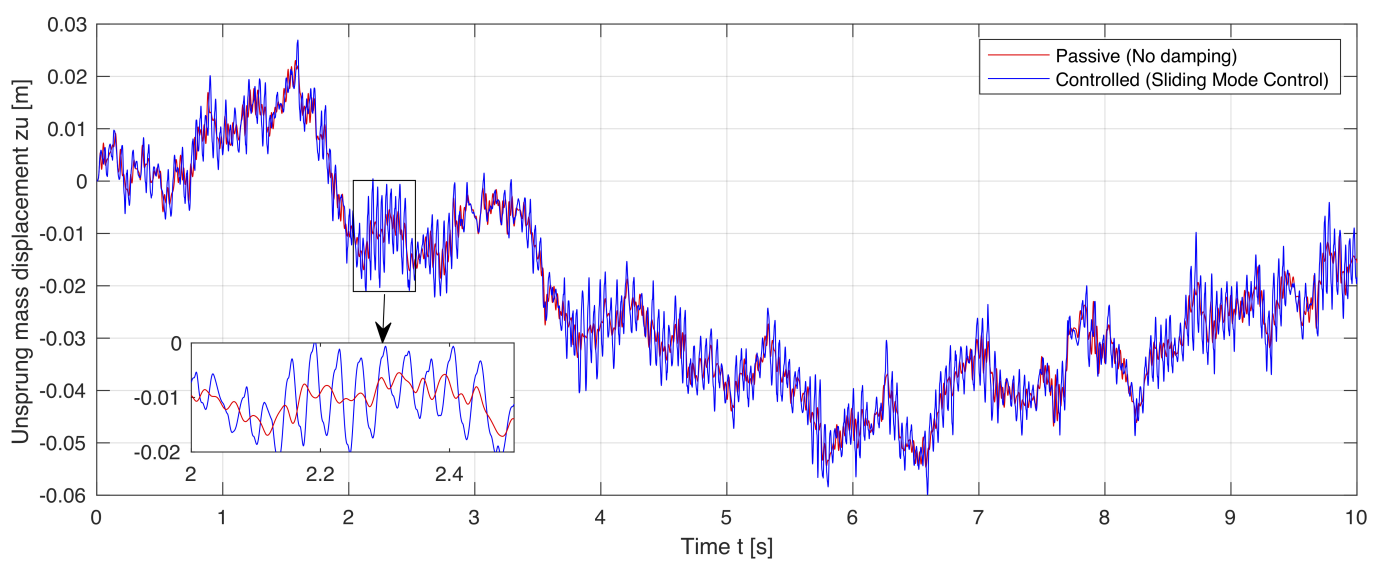

(a) Unsprung mass displacement when $\alpha=1$.



(b) Unsprung mass displacement when $\alpha=0$.



(c) Unsprung mass displacement when $\alpha=0.6$.

Figure 10. The simulation of passive and controlled unsprung mass displacements.

\section{Conclusions and Perspectives}

This paper investigated a new technique for modelling, simulation and control of semi-active suspension systems supporting both ride comfort and road-holding driving characteristics and the implementation of the technique in accordance with the functional mock-up interface standard FMI 2.0. Through a parametric approach, the study provided a control-oriented hybrid model of a quarter car semi-active suspension system. The quarter car hybrid model was then used to develop a sliding 
mode controller that supports both ride comfort and road-holding capability. The proposed methods were validated through a prototype implementation and experimental simulation.

The work presented in this paper can be continued in many different directions. In the future, we want to explore the applicability of our methods for vehicle suspension models having more degrees of freedom. In particular, we aim to explore the applicability of our proposed methods for half car suspension models having four degrees of freedom and full car suspension models having seven degrees of freedom, including pitching and rolling car dynamics. Furthermore, we want to explore techniques for detecting and eliminating chattering behaviour in vehicle suspension systems.

Author Contributions: Conceptualization, A.A. and M.F.; methodology, methods and analysis, A.A.; software and validation, A.A.; writing, draft preparation, review and editing, A.A. and M.F., All authors read and agreed to the published version of the manuscript.

Funding: This research received no external funding.

Conflicts of Interest: The authors declare no conflict of interest.

\section{References}

1. Yagiz, N.; Hacioglu, Y. Backstepping control of a vehicle with active suspensions. Control. Eng. Pract. 2008, 16, 1457-1467. [CrossRef]

2. Ribbens, W.B. Chapter 7-Vehicle Motion Controls. In Understanding Automotive Electronics, 8th ed.; Butterworth-Heinemann: Oxford, UK, 2017; pp. 343-408. ISBN 9780128104347.

3. Nekoui, M.A.; Hadavi, P. Optimal control of an active suspension system. In Proceedings of the 14th International Power Electronics and Motion Control Conference, Ohrid, Macedonia, 6-8 September 2010; Volume 16, ISBN 978-1-4244-7856-9, doi:10.1109/EPEPEMC.2010.5606776. [CrossRef]

4. Alvarez-Sanchez, E. A Quarter-Car Suspension System: Car Body Mass Estimator and Sliding Mode Control. Procedia Technol. 2013, 7, 208-214. [CrossRef]

5. Yerrawar, R.N.; Arakerimath, R.R. Performance assessment and control policies for semiactive suspension using SIMSCAPE. In Proceedings of the 2016 International Conference on Automatic Control and Dynamic Optimization Techniques (ICACDOT), Pune, India, 9-10 September 2016; pp. 1163-1168.

6. Gandhi, P.; Adarsh, S.; Ramachandran, K.I. Performance Analysis of Half Car Suspension Model with 4 DOF using PID, LQR, FUZZY and ANFIS Controllers. Procedia Comput. Sci. 2017, 115, 2-13. [CrossRef]

7. Chen, Y. Skyhook Surface Sliding Mode Control on Semi-Active Vehicle Suspension System for Ride Comfort Enhancement. Engineering, 2009, 1, 23-32, doi:10.4236/eng.2009.11004. [CrossRef]

8. Savaresi, S.; Silani, E.; Bittanti, S. Acceleration driven damper (ADD): An optimal control algorithm for comfort oriented semi-active suspensions. ASME Trans. J. Dyn. Syst. Meas. Control. 2005, 127, 218-229. [CrossRef]

9. Savaresi, S.; Spelta, C. Mixed skyhook and ADD: Approaching the filtering limits of a semi-active suspension. ASME Trans. J. Dyn. Syst. Meas. Control. 2007, 129, 382-392. [CrossRef]

10. Choi, S.B.; Lee, S.K.; Park, Y.P. A hysteresis model for the field-dependent damping force of a magnetorheological damper. J. Sound Vib. 2001, 245, 375-383. [CrossRef]

11. Gaul, L.; Nitsche, R. Friction control for vibration suppression. Mech. Syst. Signal Process. 2000, 14, 139-150. [CrossRef]

12. Kim, Y.; Langari, R.; Hurlebaus, S. Semiactive nonlinear control of a building with a magnetorheological damper system. Mech. Syst. Signal Process. 2009, 23, 300-315. [CrossRef]

13. Kamath, G.M.; Wereley, N.M. A nonlinear viscoelastic-plastic model for electrorheological fluids. Smart Mater. Struct. 1997, 6, 351. [CrossRef]

14. Dyke, S.; Spencer Jr, B.; Sain, M.; Carlson, J. Modeling and control of magnetorheological dampers for seismic response reduction. Smart Mater. Struct. 1996, 5, 565. [CrossRef]

15. Guo, S.; Yang, S.; Pan, C. Dynamic modeling of magnetorheological damper behaviors. J. Intell. Mater. Syst. Struct. 2006, 17, 3-14. [CrossRef]

16. Makris, N.; Burton, S.A.; Taylor, D.P. Electrorheological damper with annular ducts for seismic protection applications. Smart Mater. Struct. 1996, 5, 551. [CrossRef] 
17. Unger, A.; Schimmack, F.; Lohmann, B.; Schwarz, R. Application of LQ-based semi-active suspension control in a vehicle. Control. Eng. Pract. 2013, 21, 1841-1850. [CrossRef]

18. Fallah, M.S.; Bhat, R.; Xie, W.F. Ho robust control of semi-active Macpherson suspension system: New applied design. Veh. Syst. Dyn. 2010, 48, 339-360. [CrossRef]

19. Passenberg, B.; Caines, P.E.; Leibold, M.; Stursberg, O.; Buss, M. Optimal control for hybrid systems with partitioned state space. IEEE Trans. Autom. Control. 2013, 58, 2131-2136. [CrossRef]

20. Prabakar, R.S.; Sujatha, C.; Narayanan S. Optimal semi-active preview control response of a half car vehicle model with magnetorheological damper. J. Sound Vib. 2009, 326, 400-420. [CrossRef]

21. Zareh, S.H.; Khayyat, A.A.A. Fuzzy inverse model of magnetorheological dampers for semi-active vibration control of an eleven-degrees of freedom suspension system. J. Syst. Des. Dyn. 2011, 5, 1485-1497. [CrossRef]

22. Takahashi, M.; Kumamaru, T.; Yoshida, K. Integrated controller design for automotive semi-active suspension considering vehicle behavior with steering input. J. Syst. Des. Dyn. 2010, 4, 712-724. [CrossRef]

23. Rao, K.D. Modeling, Simulation and Control of Semi Active Suspension System for Automobiles under MATLAB Simulink using PID Controller. IFAC Proc. Vol. 2014, 47, 827-831. [CrossRef]

24. Zapateiro, M.; Luo, N.; Karimi, H.R.; Vehi, J. Vibration control of a class of semiactive suspension system using neural network and backstepping techniques. Mech. Syst. Signal Process. 2009, 23, 1946-1953. [CrossRef]

25. Guo, D.L.; Hu, H.Y.; Yi, J.Q. Neural network control for a semi-active vehicle suspension with a magnetorheological damper. J. Vib. Control. 2004, 10, 461-471. [CrossRef]

26. Sun, L.; Cai, X.; Yang, J. Genetic algorithm-based optimum vehicle suspension design using minimum dynamic pavement load as a design criterion. J. Sound Vib. 2007, 301, 18-27. [CrossRef]

27. Available online: https://fmi-standard.org/ (accessed on 11 January 2020).

28. Aljarbouh, A.; Caillaud, B. Chattering-free simulation of hybrid dynamical systems with the functional mock-up interface 2.0. In Proceedings of the First Japanese Modelica Conferences, Tokyo, Japan, 23-24 May 2016; Volume 124, pp. 95-105. doi:10.3384/ecp1612495. [CrossRef]

29. Aljarbouh, A.; Caillaud, B. On the Regularization of Chattering Executions in Real Time Simulation of Hybrid Systems. In Proceedings of the Baltic Young Scientists Conference, the 11th Baltic Young Scientists Conference, Tallinn, Estonia, 10-14 August 2015; p. 49. Available online: https:/ / hal.archives-ouvertes.fr/hal-01246853 (accessed on 14 January 2020).

30. Aljarbouh, A.; Caillaud, B. Simulation for hybrid systems: Chattering path avoidance. In Proceedings of the 56th Conference on Simulation and Modelling (SIMS 56), Linkoping, Sweden, 7-9 October 2015; Volume 119, pp. 175-185.doi:10.3384/ecp15119175. [CrossRef]

31. Aljarbouh, A.; Zeng, Y.; Duracz, A.; Caillaud, B.; Taha, W. Chattering-free simulation for hybrid dynamical systems semantics and prototype implementation. In Proceedings of the 19th IEEE International Conference on Computational Science and Engineering (CSE) and IEEE International Conference on Embedded and Ubiquitous Computing (EUC) and 15th International Symposium on Distributed Computing and Applications for Business Engineering (DCABES), Paris, France, 24-26 August 2016; pp. 412-422. [CrossRef]

32. Aljarbouh, A. Non-standard zeno-free simulation semantics for hybrid dynamical systems. In Verification and Evaluation of Computer and Communication Systems; Springer International Publishing: Cham, Switzerland, 2019; pp. 16-31.

33. Choi, S.B. Vibration control of electrorheological seat suspension with human-body model using sliding mode control. J. Sound Vib. 2007, 303, 391-404. [CrossRef]

(C) 2020 by the authors. Licensee MDPI, Basel, Switzerland. This article is an open access article distributed under the terms and conditions of the Creative Commons Attribution (CC BY) license (http:/ / creativecommons.org/licenses/by/4.0/). 